\title{
Propriedades físicas do solo em sistemas de rotação de culturas conforme o uso de corretivos da acidez
}

\author{
Gustavo Spadotti Amaral Castro(1), Juliano Carlos Calonego(2) e Carlos Alexandre Costa Crusciol(1)
}

\begin{abstract}
(1)Universidade Estadual Paulista, Faculdade de Ciências Agronômicas, Departamento de Produção Vegetal, Campus de Botucatu, Caixa Postal 237, CEP 18603-970 Botucatu, SP. E-mail: gsacastro@hotmail.com, crusciol@fca.unesp.br (2)Universidade do Oeste Paulista, Centro de Ciências Agrárias, Rodovia Raposo Tavares, Km 572, CEP 19067-175 Presidente Prudente, SP. E-mail: juliano@unoeste.br
\end{abstract}

Resumo - O objetivo deste trabalho foi avaliar o efeito de sistemas de rotação de culturas e de corretivos da acidez nas propriedades físicas do solo. O experimento foi realizado entre outubro de 2006 e julho de 2008, em Botucatu, SP, em blocos ao acaso, com parcelas subdivididas e oito repetições. As parcelas foram constituídas por quatro sistemas de rotação: soja/pousio/milho/pousio, soja/aveia-branca/milho/feijão, soja/milheto/milho/ guandu e soja/braquiária/milho/braquiária. As subparcelas consistiram do tratamento testemunha, sem correção, e da aplicação de 3,8 $\mathrm{Mg} \mathrm{ha}^{-1}$ de calcário dolomítico (PRNT $=90 \%$ ) ou de 4,1 $\mathrm{Mg} \mathrm{ha}^{-1}$ de silicato de cálcio e magnésio (PRNT $=80 \%$ ), na superfície de um Latossolo Vermelho argiloso. Foram determinadas: estabilidade de agregados, densidade do solo, porosidade total, macro e microporosidade, resistência do solo à penetração e umidade do solo. A aplicação dos corretivos de acidez em superfície não reduz a agregação do solo e aumenta a macroporosidade até $0,20 \mathrm{~m}$ de profundidade, após aplicação de silicato, e até $0,10 \mathrm{~m}$, após aplicação de calcário. A manutenção do solo em pousio, na entressafra, prejudica a estruturação do solo, reduz a estabilidade de agregados e aumenta a resistência à penetração nas camadas superficiais. A semeadura de braquiária, entre as safras de verão, aumenta a estabilidade de agregados até $0,10 \mathrm{~m}$ de profundidade.

Termos para indexação: calagem, estabilidade de agregados, plantas de cobertura, plantio direto, pousio, silicatagem.

\section{Soil physical properties in crop rotation systems as affected by liming materials}

\begin{abstract}
The objective of this work was to evaluate the effects of crop rotation systems and liming materials on soil physical properties. The experiment was carried out from October 2006 to July 2008, in Botucatu, SP, Brazil, in a completely randomized block design in a split-plot arrangement with eight replicates. Main plots consisted of four crop rotation systems: soybean/fallow/maize/fallow, soybean/white-oat/maize/bean, soybean/millet/maize/pigeon pea and soybean/signal grass/maize/signal grass. Subplots consisted of the control treatment, without soil correction, and of the application of $3.8 \mathrm{Mg} \mathrm{ha}^{-1}$ of dolomitic lime (ECC $\left.=90 \%\right)$ or $4.1 \mathrm{Mg} \mathrm{ha}^{-1}$ of calcium-magnesium silicate $(\mathrm{ECC}=80 \%)$, on the surface of a clayed Rhodic Ferralsol. Aggregate stability, soil bulk density, total porosity, macro and microporosity, soil penetration resistance and moisture content were evaluated. Superficial application of the lime materials does not reduce soil aggregation and increases macroporosity down to $0.20 \mathrm{~m}$, with calcium-magnesium silicate application, and to $0.10 \mathrm{~m}$, when lime is applied. Soil under fallow in off-season decreases aggregate stability and increases soil penetration resistance in upper layers. The cultivation of Congo signal grass, between summer crops, increases aggregate stability down to $0.10-\mathrm{m}$ depth.
\end{abstract}

Index terms: liming, aggregate stability, cover crops, no tillage system, fallow, silicate application.

\section{Introdução}

A quebra de agregados e as mudanças na estrutura do solo decorrentes de seu uso agrícola intensivo normalmente restringem o crescimento radicular e reduzem a exploração de água e nutrientes pelas culturas (Pedrotti et al., 2001). Essas alterações manifestam-se por meio de altos níveis de compactação, baixas porosidades e velocidades de infiltração de água no solo, acúmulo de água sobre a superfície e erosão hídrica (Stone \& Schlegel, 2010; Tavares Filho et al., 2010). A degradação física do solo compromete o desenvolvimento das plantas e a sustentabilidade da atividade agrícola (Albuquerque et al., 2003). 
Práticas conservacionistas, como o sistema plantio direto (SPD) e o uso de pastagens na entressafra, que revolvem menos o solo e promovem maior aporte de resíduos orgânicos, geralmente têm sido eficientes em aumentar a estabilidade de agregados (Corrêa, 2002; Salton, 2005; Calonego \& Rosolem, 2008; Blanco-Canqui et al., 2010). O maior aporte de resíduos vegetais no perfil do solo, em SPD, resulta em aumento no teor de matéria orgânica (MO), o que concorre para a formação de agregados estáveis, em razão da ação cimentante e aglutinadora que a MO exerce sobre as partículas minerais do solo (Castro Filho et al., 1998; Mielniczuk, 1999; Wohlenberg et al., 2004; Wendling et al., 2005). Além disso, as raízes atuam na estruturação do solo por meio de pressões biofísicas (axial e radial), que promovem a aproximação das partículas minerais, o que facilita sua floculação (Zonta et al., 2006). Neste sentido, a absorção de água pelas raízes também causa secamento na região adjacente às raízes, o que aumenta a coesão entre as partículas.

A aplicação de corretivos da acidez pode promover prejuízos à estabilidade de agregados e a outros atributos físicos do solo, por modificar a composição química da solução do solo. As alterações no pH, na força iônica da solução e nos tipos de íons presentes podem causar tanto a dispersão como a floculação dos coloides, com consequências diretas na agregação das partículas do solo (Seta \& Karathanasis, 1996). A ação dispersiva dos corretivos pode ser agravada em SPD, quando grandes quantidades são aplicadas na superfície do solo (Costa et al., 2004).

No entanto, Albuquerque et al. (2003), Costa et al. (2004), Griève et al. (2005) e Corrêa et al. (2009) verificaram que os corretivos da acidez também podem ter efeito indireto sobre as propriedades físicas do solo, à medida que favorecem a produção de fitomassa aérea e radicular das culturas, e aumentam a adição de matéria orgânica e a atividade microbiana no solo; fatores que auxiliam a formação dos agregados.

Estudos com rotações de culturas com espécies graníferas, forrageiras e adubos verdes, juntamente com a aplicação de corretivos na superfície do solo, em SPD, são importantes para identificar os manejos com maiores benefícios à estrutura e à conservação do solo.

O objetivo deste trabalho foi avaliar o efeito de sistemas de rotação de culturas, em SPD, e de corretivos da acidez nas propriedades físicas do solo.

\section{Material e Métodos}

O experimento foi conduzido durante duas safras agrícolas, entre outubro de 2006 e julho de 2008, na Fazenda Experimental Lageado, da Faculdade de Ciências Agronômicas da Universidade Estadual Paulista, no Município de Botucatu, SP $\left(48^{\circ} 23^{\prime} 00^{\prime \prime} \mathrm{W}\right.$ e $22^{\circ} 51^{\prime} 00^{\prime \prime} \mathrm{S}$, a $765 \mathrm{~m}$ de altitude). O solo do local é classificado como Latossolo Vermelho distroférrico típico argiloso (Santos et al., 2006). O clima predominante na região, conforme a classificação de Köppen, é do tipo Cwa, caracterizado por clima tropical de altitude, com inverno seco e verão quente e chuvoso. Antes de iniciar o experimento, em julho de 2006, foram realizadas amostragens de solo para análise dos atributos químicos (Raij et al., 2001) e físicos (Camargo et al., 2009) da área experimental (Tabela 1).

Utilizou-se o delineamento experimental de blocos ao acaso, com os tratamentos dispostos em esquema de parcelas subdivididas, com oito repetições. As parcelas consistiram de quatro sistemas de rotação de culturas na entressafra: safra/pousio; safra/safrinha; safra/ adubo verde; e safra/forrageira. Os sistemas de rotação foram os seguintes: soja/pousio/milho/pousio, soja/

Tabela 1. Propriedades químicas e físicas antes da instalação do experimento, na camada de 0 a 0,20 m de um Latossolo Vermelho argiloso.

\begin{tabular}{lc}
\hline Atributo do solo & Resultado \\
\hline $\mathrm{P}_{\text {resina }}\left(\mathrm{mg} \mathrm{dm}^{-3}\right)$ & 3,6 \\
$\mathrm{MO}\left(\mathrm{g} \mathrm{dm}^{-3}\right)$ & 18 \\
$\mathrm{pH} \mathrm{em} \mathrm{CaCl}$ & \\
$\mathrm{K}\left(\mathrm{mmol}_{\mathrm{c}} \mathrm{dm}^{-3}\right)$ & 4,2 \\
$\mathrm{Ca}\left(\mathrm{mmol}_{\mathrm{c}} \mathrm{dm}^{-3}\right)$ & 0,7 \\
$\mathrm{Mg}\left(\mathrm{mmol}_{\mathrm{c}} \mathrm{dm}^{-3}\right)$ & 12 \\
$\mathrm{H}+\mathrm{Al}\left(\mathrm{mmol}_{\mathrm{c}} \mathrm{dm}^{-3}\right)$ & 6 \\
$\mathrm{Al}\left(\mathrm{mmol}_{\mathrm{c}} \mathrm{dm}^{-3}\right)$ & 54 \\
$\mathrm{Si}\left(\mathrm{mg} \mathrm{dm}^{-3}\right)$ & 4 \\
$\mathrm{~V}(\%)$ & 6,2 \\
Areia $\left(\mathrm{g} \mathrm{kg}^{-1}\right)$ & 25 \\
Argila $\left(\mathrm{g} \mathrm{kg}^{-1}\right)$ & 469 \\
$\mathrm{Silte}\left(\mathrm{g} \mathrm{kg}^{-1}\right)$ & 440 \\
Diâmetro médio ponderado $(\mathrm{mm})$ & 91 \\
Diâmetro médio geométrico $(\mathrm{mm})$ & 2,9 \\
Índice de estabilidade de agregados $(\%)$ & 2,8 \\
Densidade do solo $\left(\mathrm{Mg} \mathrm{m}^{-3}\right)$ & 99 \\
Porosidade total $\left(\mathrm{m}^{3} \mathrm{~m}^{-3}\right)$ & 1,40 \\
Microporosidade $\left(\mathrm{m}^{3} \mathrm{~m}^{-3}\right)$ & 0,39 \\
Macroporosidade $\left(\mathrm{m}^{3} \mathrm{~m}^{-3}\right)$ & 0,32 \\
\hline
\end{tabular}


aveia-branca/milho/feijão, soja/milheto/milho/guandu e soja/braquiária/milho/braquiária. As subparcelas foram constituídas por duas fontes de corretivos calcário dolomítico e silicato de cálcio e magnésio e uma testemunha sem correção do solo. As parcelas apresentavam as dimensões de $5,4 \mathrm{~m}$ de largura e $30 \mathrm{~m}$ de comprimento, com $162 \mathrm{~m}^{2}$; já as subparcelas, apresentavam 5,4 $\mathrm{m}$ de largura e $10 \mathrm{~m}$ de comprimento, com total de $54 \mathrm{~m}^{2}$. A área útil foi constituída pelas linhas centrais, tendo-se desprezado uma linha de cada lado das subparcelas e $1 \mathrm{~m}$ nas extremidades.

As doses de corretivos foram calculadas para elevar a saturação por bases (V) a 70\%. Assim, em outubro de 2006, antes da semeadura da primeira safra agrícola, foram aplicados 3,8 $\mathrm{Mg} \mathrm{ha}^{-1}$ de calcário dolomítico $(\mathrm{PRNT}=90 \%, \mathrm{CaO}=36 \%$ e $\mathrm{MgO}=12 \%)$ e $4,1 \mathrm{Mg}$ $\mathrm{ha}^{-1}$ de silicato de cálcio e magnésio (PRNT $=80 \%$, $\mathrm{CaO}=34 \%, \mathrm{MgO}=10 \%$ e $\mathrm{SiO}_{2}=22 \%$ ).

Em 29/11/2006, a cultura da soja, cultivar Embrapa 48, foi semeada com espaçamento de $0,45 \mathrm{~m}$ entre linhas e 22 plantas por metro. Para a adubação de base nos sulcos, foram utilizados $250 \mathrm{~kg} \mathrm{ha}^{-1} \mathrm{da}$ fórmula N-P-K (04-20-20). Após 50 dias da semeadura, ocorreu o florescimento da cultura, e a colheita foi realizada em 3/4/2007.

As culturas de entressafra (milheto, aveia-branca e braquiária) foram semeadas em 10/4/2007, também no espaçamento de $0,45 \mathrm{~m}$ entre linhas. Após 30 dias da semeadura, todas as culturas foram adubadas com $40 \mathrm{~kg} \mathrm{ha}^{-1} \mathrm{de} \mathrm{N}$, na forma de ureia. Para a semeadura do milheto (cultivar BRS 1501), utilizou-se $25 \mathrm{~kg} \mathrm{ha}^{-1}$ de sementes, para obter uma população de $300 \mathrm{mil}$ plantas por hectare. O florescimento pleno ocorreu aos 50 dias após a semeadura, quando foi realizado o manejo de corte nas plantas, a $15 \mathrm{~cm}$ do solo, para estimular a rebrota. Trinta e cinco dias após essa operação, quando as plantas atingiram novamente o estádio de florescimento, foi realizado mais um corte, rente ao solo. Para a aveia-branca, utilizou-se a cultivar IAC 7, tendo-se semeado 133 sementes viáveis por metro quadrado. A cultura também floresceu 50 dias após a semeadura, e a colheita ocorreu em 30/7/2007. Como forrageira, utilizou-se Urochloa ruziziensis (Syn. Brachiaria ruziziensis), com uso de $10 \mathrm{~kg} \mathrm{ha}^{-1}$ de sementes com valor cultural de $25 \%$, para semear $2,5 \mathrm{~kg} \mathrm{ha}^{-1} \mathrm{de}$ sementes puras. A braquiária permaneceu vegetando até dezembro de 2007, antes do plantio da outra cultura de verão. O restante da área experimental permaneceu em pousio, da colheita da soja até a semeadura da safra seguinte.

No segundo ano agrícola, a semeadura do híbrido de milho 2B570 foi realizada em 2/12/2007, em toda área experimental, no espaçamento de $0,45 \mathrm{~m}$ entre linhas, com as sementes necessárias para se obter três plantas por metro. A adubação de semeadura foi $300 \mathrm{~kg} \mathrm{ha}^{-1}$ da fórmula N-P-K (08-28-16). Posteriormente, em $10 / 1 / 2008$, realizou-se adubação de cobertura com $90 \mathrm{~kg} \mathrm{ha}^{-1}$ de $\mathrm{N}$, na forma de ureia, na entrelinha das parcelas. O florescimento pleno do milho ocorreu 64 dias após sua emergência, e a colheita foi realizada em $1 / 4 / 2008$.

Nessa entressafra, assim como na anterior, a área experimental foi novamente seccionada em quatro faixas, das quais três foram ocupadas por culturas e uma foi mantida em pousio. As culturas de entressafra foram semeadas em $5 / 4 / 2008$, seguindo o espaçamento de $0,45 \mathrm{~m}$ entre linhas. Trinta dias após a semeadura, as culturas foram adubadas com $40 \mathrm{~kg} \mathrm{ha}^{-1}$ de $\mathrm{N}$ na forma de ureia. A cultura do feijão, cultivar Pérola, foi semeada com uso de 18 sementes por metro. O florescimento pleno ocorreu 47 dias após a semeadura, e a colheita foi realizada em 29/6/2008. Para a cultura do guandu, foram semeadas 20 sementes por metro da cultivar Iapar 43. O florescimento pleno ocorreu em 1/7/2008, quando a cultura foi dessecada. A braquiária foi implantada na mesma densidade do primeiro ano, tendo permanecido em livre crescimento até outubro de 2008. Mais uma vez, o restante da área experimental permaneceu em pousio, da colheita do milho até a amostragem do solo. Para todas as culturas de verão e para as culturas dos tratamentos safrinha e adubo verde, procedeu-se à coleta da parte aérea das culturas no momento do florescimento pleno. Nos demais tratamentos (pousio e forrageira), a coleta para determinação de produção de matéria seca foi realizada antes da semeadura de verão do ano agrícola seguinte. $\mathrm{O}$ material vegetal coletado foi seco em estufa a $65^{\circ} \mathrm{C}$ até atingir massa constante. Em seguida, os dados foram transformados em kg ha-1.

Em outubro de 2008, foram abertas trincheiras em cada subparcela e coletadas amostras de solo com estrutura não deformada, para determinação de densidade do solo (Ds), macroporosidade, microporosidade e porosidade total $(\mathrm{Pt})$, por meio de anéis volumétricos com $0,05 \mathrm{~m}$ de diâmetro e $0,05 \mathrm{~m}$ de altura. As amostras foram retiradas em duplicata, 
no centro das camadas de $0-0,10,0,10-0,20$ e 0,20 $0,40 \mathrm{~m}$. Em laboratório, as amostras foram colocadas para saturar em bandejas de plástico com água até $2 / 3$ da altura dos anéis, por 48 horas. Após pesagem das amostras saturadas com água, elas foram levadas à mesa de tensão e submetidas à tensão de 0,006 MPa. Após o equilíbrio ter sido atingido, nesse potencial matricial, as amostras foram pesadas e colocadas para secar a $105^{\circ} \mathrm{C}$, em estufa de aeração forçada, por 24 horas. As amostras secas foram pesadas novamente, $\mathrm{e}$, com a diferença entre a massa das amostras saturadas com água e a das secas a $105^{\circ} \mathrm{C}$, calculou-se a Pt. Para calcular a Ds, dividiu-se a massa das amostras secas a $105^{\circ} \mathrm{C}$ pelo volume do anel volumétrico. A macro e a microporosidade foram determinadas com uso do teor de água retida nas amostras em equilíbrio com tensão de 0,006 MPa, tendo-se considerado que essa tensão é suficiente para retirar toda a água retida nos macroporos e que a água restante representa o volume de microporos. Assim, a partir do conhecimento da porosidade total e da microporosidade, foi possível calcular a macroporosidade (Camargo et al., 2009).

Para a avaliação da estabilidade dos agregados, foram coletados, com o auxílio de espátulas, monólitos com dimensões aproximadas de $0,05 \mathrm{~m}$ de altura, $0,10 \mathrm{~m}$ de largura e 0,15 $\mathrm{m}$ de comprimento. Foram coletadas quatro amostras de solo por subparcela, no centro das camadas de $0-0,10,0,10-0,20$ e 0,20 $0,40 \mathrm{~m}$. As amostras foram acondicionadas em sacos de plástico e, posteriormente, pré-selecionadas em um jogo de peneiras sobrepostas, com a peneira superior e a inferior tendo malhas de 8 e $4 \mathrm{~mm}$, respectivamente. Para a avaliação da estabilidade dos agregados, utilizou-se a porção que passou pela malha de $8 \mathrm{~mm}$ e ficou retida na de $4 \mathrm{~mm}$.

Para avaliar a estabilidade de agregados via úmida, adotou-se o procedimento descrito em Camargo et al. (2009). Foram usados $25 \mathrm{~g}$ de solo de cada amostra, pré-umedecidas e mantidas em repouso em temperatura ambiente por $10 \mathrm{~min}$. Em seguida, essas amostras foram colocadas no aparelho de oscilação vertical (tipo Yoder), sobre um conjunto de peneiras de $2,00,1,00,0,50,0,25$ e 0,105 mm de diâmetro. Após $15 \mathrm{~min}$, as porções retidas em cada peneira foram transferidas para potes de alumínio, com auxílio de jatos de água, e secas em estufa a $105^{\circ} \mathrm{C}$, por 24 horas, para posterior pesagem. A partir dos valores dessas massas e dos teores de umidade das amostras de solo submetidas ao tamisamento, foram calculados a percentagem de agregados retidos na peneira de $2 \mathrm{~mm}$ (agregados $>2 \mathrm{~mm}$ ), o diâmetro médio ponderado (DMP), o diâmetro médio geométrico (DMG) e o índice de estabilidade de agregados (IEA), de acordo com Kemper \& Chepil (1965), com uso das seguintes equações:

$$
\begin{gathered}
\text { DMP }=\sum_{i=1}^{n}\left(x_{i} \times w_{i}\right) \\
D M G=\left(\exp \sum_{i=1}^{n}\left(w_{p} \times \log x_{i}\right)\right) /\left(\sum_{i=1}^{n} w_{i}\right)
\end{gathered}
$$

$\mathrm{IEA}=100\left(\right.$ peso da amostra seca $\left.-\mathrm{w}_{\mathrm{p} 25}\right) /$ peso da amostra seca, em que: $\mathrm{x}_{\mathrm{i}}$ é o diâmetro médio das classes de agregados; $\mathrm{w}_{\mathrm{i}}$ é a proporção da massa de agregados de cada classe em relação ao total; $\mathrm{w}_{\mathrm{p}}$ é a massa de agregados de cada classe; e $\mathrm{w}_{\mathrm{p} 25}$ é a massa de agregados das classes menores que $0,25 \mathrm{~mm}$.

Por ocasião da coleta de solo, determinou-se a resistência mecânica do solo à penetração, ao longo do perfil, por meio de penetrômetro hidráulico-eletrônico, desenvolvido por Santos \& Lanças (1999). Foram realizadas duas perfurações por subparcela, até a profundidade de $0,40 \mathrm{~m}$. No mesmo instante, coletaram-se duas amostras deformadas de solo nas profundidades de $0,05,0,15$ e $0,30 \mathrm{~m}$, para determinação da umidade do solo, as quais foram acondicionadas no interior de sacos de plástico vedados e em caixas de isopor para conservação da umidade. Em seguida, foram determinados os teores de água das amostras, em laboratório, pelo método gravimétrico (Carmargo et al., 2009).

Os resultados foram submetidos à análise de variância, a 5\% de probabilidade, tendo-se comparado as médias pelo teste $\mathrm{t}$ (DMS), também a $5 \%$ de probabilidade.

\section{Resultados e Discussão}

A produção de matéria seca acumulada durante as duas safras agrícolas foi influenciada pelos corretivos e pelos sistemas de rotação de culturas, sem interação significativa entre os fatores (Tabela 2). Os corretivos da acidez do solo elevaram a produção de matéria seca das culturas, o que resultou em maior aporte de palhada à superfície do solo. Quanto aos sistemas de rotação de culturas, a maior produção de matéria seca foi observada no sistema rotacionado com forrageira, seguido pelo sistema com adubo verde, no qual se cultivou milheto e guandu na entressafra. $\mathrm{O}$ sistema 
rotacionado com safrinha, cuja entressafra constou de aveia-branca e feijão, não diferiu do sistema pousio quanto à produção total de matéria seca, provavelmente pela baixa produção de palha do feijão.

Não houve interação significativa entre os corretivos da acidez e os sistemas de rotação de culturas, para os atributos avaliados (Tabela 3). Houve efeito significativo dos corretivos da acidez para a macroporosidade do solo, nas camadas de $0-0,10$ e de $0,10-0,20 \mathrm{~m}$, e dos sistemas de rotação de culturas para IEA, na camada de $0-0,10 \mathrm{~m}$. Densidade do solo, porosidade total, microporosidade, DMG e DMP não foram afetados pela aplicação de corretivos nem pelos sistemas de rotação de culturas.

A calagem e a silicatagem elevaram a macroporosidade na camada de $0-0,10 \mathrm{~m}$, em comparação ao tratamento testemunha. Na camada de $0,10-0,20 \mathrm{~m}$, a macroporosidade manteve-se maior no tratamento com aplicação de silicato do que no com ausência do corretivo, porém sem diferir do tratamento com calagem (Figura 1). Em solos com baixa proporção de macroporos, como é caso do solo da área experimental (Tabela 1), é importante a utilização de práticas de

Tabela 2. Médias e valores de F para a produção de matéria seca $\left(\mathrm{kg} \mathrm{ha}^{-1}\right)$ durante as duas safras agrícolas, em razão da aplicação superficial de corretivos e de sistemas de rotação de culturas em plantio direto ${ }^{(1)}$.

\begin{tabular}{lc}
\hline Tratamento & Massa de matéria seca acumulada ${ }^{(2)}$ \\
\hline Testemunha & Corretivos \\
Calcário & $22.640 \mathrm{~b}$ \\
Silicato & $29.770 \mathrm{a}$ \\
\hline Diferença mínima significativa & $30.670 \mathrm{a}$ \\
CV (\%) & 4.412 \\
& 10,11 \\
Pousio & Sistemas \\
Adubo verde & $24.660 \mathrm{c}$ \\
Safrinha & $28.980 \mathrm{~b}$ \\
Forrageira & $25.230 \mathrm{c}$ \\
Diferença mínima significativa & $31.820 \mathrm{a}$ \\
CV (\%) & 3.059 \\
Valor de F & 11,64 \\
Corretivos (C) & \\
Sistemas (S) & $5,94^{*}$ \\
C x S & $13,33^{* *}$ \\
\hline
\end{tabular}

${ }^{(1)}$ Médias seguidas de letras iguais não diferem entre si pelo teste de Tukey, a $5 \%$ de probabilidade. ${ }^{(2)}$ Soma da produção de matéria seca de todos os

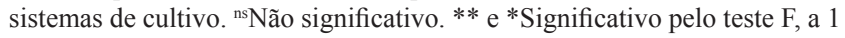
e $5 \%$ de probabilidade, respectivamente. manejo que aumentem a macroporosidade, para melhoria da aeração do solo (Tormena et al., 1998). Apesar do aumento observado na macroporosidade, nos tratamentos com a aplicação dos corretivos, a macroporosidade não ficou acima do valor mínimo de $10 \%$, preconizado como limite crítico para que não ocorra limitação na aeração do solo (Grable \& Siemer, 1968; Jong van Lier, 2010).

A ausência de efeito negativo de corretivos da acidez na agregação do solo também foi observada por Albuquerque et al. (2000, 2003) e Costa et al. (2004), embora esses autores tenham verificado aumento no teor de argila dispersa e redução do grau de floculação, normalmente associados à desestruturação do solo (Zonta et al., 2006). No entanto, de acordo com Chan \& Heenan (1999), Albuquerque et al. (2000, 2003), Costa et al. (2004) e Griève et al. (2005), o aporte de $\mathrm{C}$ e o aumento da atividade microbiana ou do sistema radicular das culturas, resultantes da aplicação de corretivos da acidez do solo, contribuem para a manutenção da estabilidade de agregados, o que poderia ter compensado o efeito dispersante dos corretivos. Assim, os benefícios proporcionados pelos corretivos à produção de matéria seca, durante as duas safras agrícolas (Tabela 2), pode ter minimizado o efeito deletério da dispersão da argila, que teria culminado na redução da macroporosidade (Tabela 3). Neste sentido, Bortoluzzi et al. $(2008,2010)$ relataram melhorias nos atributos físicos em solos que receberam corretivos da acidez. Pértile (2011), ao avaliar o efeito de calcário e resíduo alcalino da indústria de celulose, como corretivos da acidez, nos atributos físicos e químicos do solo, não constatou interferência desses insumos na estrutura do solo, e sim melhorias químicas no perfil do solo, que proporcionaram maior crescimento das raízes do feijoeiro.

Os sistemas de produção agrícola afetaram o IEA (Figura 2). No tratamento com menor aporte de material vegetal, em que se utilizou apenas uma cultura no verão e pousio na entressafra, o IEA foi menor na camada de $0-0,10 \mathrm{~m}$. O sistema com cultivo de forrageira (braquiária) aumentou o IEA nessa camada, o que está de acordo com o observado por Cunha et al. (2007). Segundo Bayer \& Mielniczuk (2008), os sistemas radiculares das plantas forrageiras tropicais apresentam boa eficiência na agregação dos solos. Os sistemas que incluiram o cultivo de culturas de safrinha e de adubos verdes apresentaram resultados intermediários 
ao cultivo da braquiária e de pousio na entressafra. Além do efeito do sistema radicular, as culturas de entressafra proporcionam maior aporte de resíduos orgânicos ao sistema. Huang et al. (2010) verificaram que a aplicação de quantidades elevadas de resíduos orgânicos, via adubo verde, influencia positivamente a agregação do solo.

São comuns, na literatura, relatos de maior efeito das plantas com sistema radicular fasciculado na estruturação do solo (Silva \& Mielniczuk, 1997; Calonego \& Rosolem, 2008). Para Salton et al. (2008), as gramíneas apresentam maior efeito na agregação do solo, em virtude de seu abundante sistema radicular. De acordo com Bayer \& Mielniczuk (2008), sistemas de manejo que aumentem o crescimento e a distribuição de raízes no perfil do solo propiciam maior estabilidade de agregados, pois, além de aumentar a disponibilidade de substâncias agregadoras, como matéria orgânica e exsudados radiculares, também promovem aproximação e maior interação entre as partículas minerais do solo. Além disso, o secamento na região adjacente às raízes promove a coesão entre essas partículas (Zonta et al., 2006).

As diferenças entre os sistemas de produção na estabilidade de agregados foram observadas apenas na camada de $0-0,10 \mathrm{~m}$, o que pode ser atribuído ao fato de essa ser a camada do solo onde se concentram os depósitos de resíduos vegetais das plantas de cobertura e onde ocorre maior colonização das raízes (Garcia \& Rosolem, 2010). Segundo Cunha et al. (2007), o efeito dos sistemas de manejo na estabilidade de agregados se limita aos primeiros centímetros do solo, por ser a camada em que os teores de MO são mais afetados pelo manejo do solo. Além disso, em se tratando de avaliações da física do solo, dois anos de aplicação dos tratamentos é um período de tempo relativamente curto. Portanto, interferências em maiores profundidades no perfil são esperadas a médio e longo prazo (Blanco-Canqui et al., 2010).

Tabela 3. Valores de F e médias de densidade do solo (Ds), resistência à penetração (RP), umidade (Um), porosidade total (PT), microporosidade (Mic), macroporosidade (Mac), diâmetro médio ponderado (DMP), diâmetro médio geométrico (DMG) e índice de estabilidade de agregados (IEA), nas camadas de solo de 0-0,10, 0,10-0,20 e 0,20-0,40 m, em função da aplicação de corretivos e de sistemas de rotação de culturas em plantio direto.

\begin{tabular}{|c|c|c|c|c|c|c|c|c|c|}
\hline Tratamento & $\begin{array}{c}\text { Ds } \\
\left(\mathrm{g} \mathrm{cm}^{-3}\right)\end{array}$ & $\begin{array}{c}\text { RP } \\
\text { (Mpa) }\end{array}$ & $\begin{array}{l}\text { Um } \\
(\%)\end{array}$ & \multicolumn{3}{|c|}{ 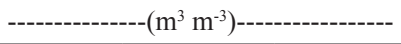 } & \multicolumn{2}{|c|}{---------(mm)-------- } & $\begin{array}{l}\text { IEA } \\
(\%)\end{array}$ \\
\hline & \multicolumn{9}{|c|}{$0-0,10 \mathrm{~m}$} \\
\hline Corretivos (C) & $0,86^{\mathrm{ns}}$ & $4,80 *$ & $0,48^{\mathrm{ns}}$ & $0,30^{\mathrm{ns}}$ & $0,23^{\mathrm{ns}}$ & $3,08^{*}$ & $0,45^{\mathrm{ns}}$ & $0,20^{\mathrm{ns}}$ & $2,14^{\mathrm{ns}}$ \\
\hline Sistemas (S) & $0,42^{\text {ns }}$ & $0,79^{\text {ns }}$ & $1,78^{\mathrm{ns}}$ & $0,69^{\text {ns }}$ & $1,00^{\mathrm{ns}}$ & $1,24^{\mathrm{ns}}$ & $1,94^{\mathrm{ns}}$ & $1,72^{\text {ns }}$ & $9,21 *$ \\
\hline $\mathrm{C} \times \mathrm{S}$ & $2,75^{\mathrm{ns}}$ & $0,39^{\text {ns }}$ & $0,55^{\mathrm{ns}}$ & $0,91^{\mathrm{ns}}$ & $1,19^{\text {ns }}$ & $1,86^{\mathrm{ns}}$ & $0,63^{\text {ns }}$ & $0,64^{\mathrm{ns}}$ & $1,80^{\mathrm{ns}}$ \\
\hline Média geral & 1,37 & $-^{(1)}$ & 1,98 & 0,40 & 0,32 & - & 18 & 1,2 & - \\
\hline CV corretivos $(\%)$ & 4,27 & 10,45 & 9,77 & 10,95 & 13,87 & 24,79 & 24,91 & 15,04 & 7,06 \\
\hline \multirow[t]{2}{*}{ CV sistemas (\%) } & 8,10 & 16,03 & 9,01 & 21,66 & 21,95 & 30,76 & 29,18 & 23,37 & 3,01 \\
\hline & \multicolumn{9}{|c|}{$0,10-0,20 \mathrm{~m}$} \\
\hline Corretivos (C) & $1,11^{\mathrm{ns}}$ & $0,47^{\mathrm{ns}}$ & $0,46^{\text {ns }}$ & $0,85^{\mathrm{ns}}$ & $2,37^{\mathrm{ns}}$ & $2,46^{*}$ & $0,85^{\mathrm{ns}}$ & $0,77^{\mathrm{ns}}$ & $0,04^{\mathrm{ns}}$ \\
\hline Sistemas (S) & $0,52^{\mathrm{ns}}$ & $0,44^{\mathrm{ns}}$ & $0,82^{\text {ns }}$ & $0,93^{\mathrm{ns}}$ & $0,32^{\text {ns }}$ & $0,71^{\mathrm{ns}}$ & $2,09^{\text {ns }}$ & $1,58^{\mathrm{ns}}$ & $0,37^{\mathrm{ns}}$ \\
\hline $\mathrm{C} \times \mathrm{S}$ & $1,93^{\text {ns }}$ & $0,58^{\mathrm{ns}}$ & $0,39^{\text {ns }}$ & $0,37^{\mathrm{ns}}$ & $0,82^{\text {ns }}$ & $1,58^{\mathrm{ns}}$ & $1,38^{\mathrm{ns}}$ & $0,66^{\mathrm{ns}}$ & $0,24^{\mathrm{ns}}$ \\
\hline Média geral & 1,37 & 2,65 & 2,59 & 0,39 & 0,35 & - & 1,4 & 0,84 & 83 \\
\hline CV corretivos $(\%)$ & 3,22 & 12,98 & 7,44 & 7,64 & 8,17 & 21,01 & 22,88 & 17,21 & 5,81 \\
\hline \multirow[t]{2}{*}{ CV sistemas (\%) } & 3,88 & 12,93 & 9,67 & 5,51 & 6,27 & 15,86 & 25,69 & 21,86 & 8,24 \\
\hline & \multicolumn{9}{|c|}{$0,20-0,40 \mathrm{~m}$} \\
\hline Corretivos (C) & $1,14^{\mathrm{ns}}$ & $0,30^{\text {ns }}$ & $0,95^{\mathrm{ns}}$ & $0,20^{\text {ns }}$ & $0,62^{\text {ns }}$ & $0,51^{\mathrm{ns}}$ & $0,35^{\text {ns }}$ & $0,40^{\text {ns }}$ & $0,65^{\mathrm{ns}}$ \\
\hline Sistemas (S) & $0,66^{\text {ns }}$ & $0,41^{\mathrm{ns}}$ & $0,61^{\mathrm{ns}}$ & $3,38^{\mathrm{ns}}$ & $1,29^{\mathrm{ns}}$ & $0,83^{\text {ns }}$ & $1,02^{\text {ns }}$ & $1,34^{\mathrm{ns}}$ & $1,73^{\mathrm{ns}}$ \\
\hline $\mathrm{C} \times \mathrm{S}$ & $1,76^{\mathrm{ns}}$ & $0,29^{\mathrm{ns}}$ & $0,67^{\mathrm{ns}}$ & $0,85^{\mathrm{ns}}$ & $1,90^{\mathrm{ns}}$ & $0,66^{\mathrm{ns}}$ & $1,15^{\mathrm{ns}}$ & $1,05^{\mathrm{ns}}$ & $0,88^{\mathrm{ns}}$ \\
\hline Média geral & 1,36 & 2,97 & 3,03 & 0,43 & 0,38 & 0,05 & 0,99 & 0,65 & 86 \\
\hline CV corretivos $(\%)$ & 13,31 & 9,67 & 8,69 & 6,15 & 5,44 & 28,17 & 25,30 & 19,35 & 6,79 \\
\hline CV sistemas (\%) & 4,28 & 10,66 & 9,11 & 2,98 & 4,77 & 22,70 & 19,69 & 18,49 & 6,48 \\
\hline
\end{tabular}

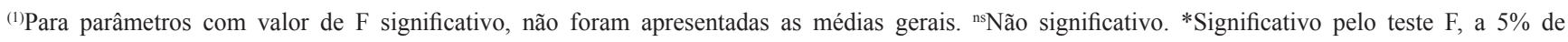
probabilidade. 
A manutenção da área em pousio por dois anos consecutivos, após o cultivo da safra de verão, resultou no aumento da resistência à penetração do solo (RP), na camada de 0-0,05 m (Figura $3 \mathrm{~A}$ ). Esse resultado pode estar relacionado à menor estruturação do solo causada

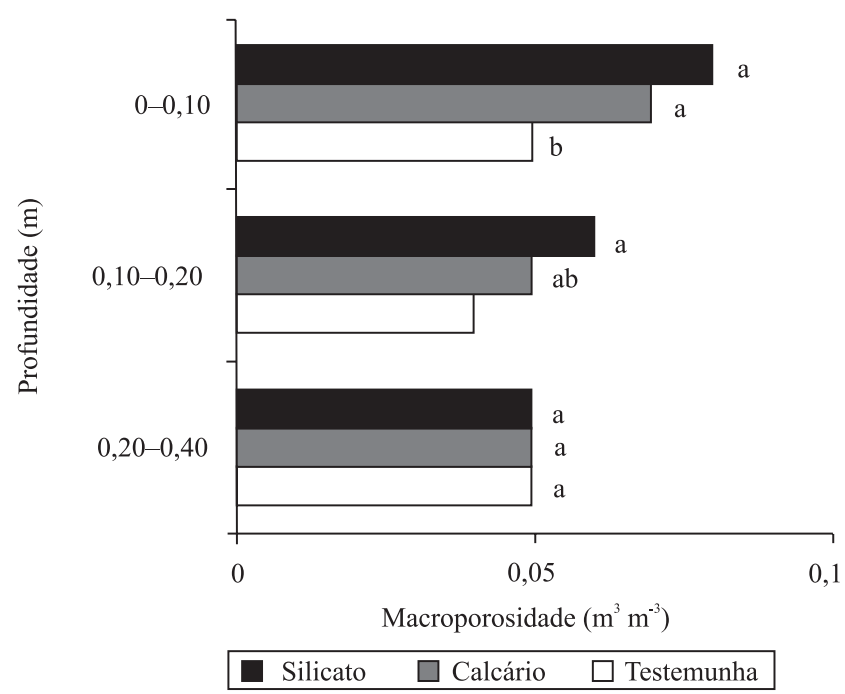

Figura 1. Macroporosidade do solo nas camadas de $0-0,10$ e 0,10-0,20 m, em função dos tratamentos com silicato e calcário. Médias seguidas de letras iguais, dentro de cada profundidade, não diferem entre si pelo teste $\mathrm{t}$, a $5 \%$ de probabilidade.

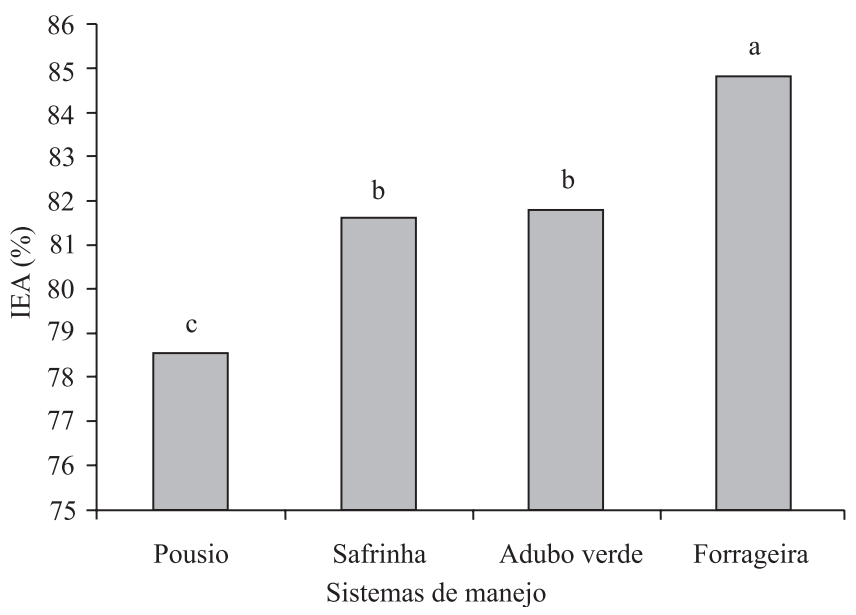

Figura 2. Índice de estabilidade de agregados do solo (IEA) na camada de $0-0,10$ m, em função dos sistemas de rotação de culturas: pousio, soja/pousio/milho/pousio; safrinha, soja/aveia-branca/milho/feijão; adubo verde, soja/milheto/ milho/guandu; forrageira, soja/braquiária/milho/braquiária. Médias seguidas de letras iguais não diferem entre si pelo teste $\mathrm{t}$, a $5 \%$ de probabilidade. por esse manejo, especialmente nessa camada do perfil (Figura 2), ou pelo fato de o solo ter apresentado menor umidade nessa camada, no momento do teste de RP (Figura 3 B). Cunha et al. (2007) observaram menor valor de RP na camada superficial $(0-0,10 \mathrm{~m})$ em tratamentos que envolveram rotações de culturas em SPD com braquiária, responsável por incrementar o teor de MO e a agregação do solo. Calonego (2007)
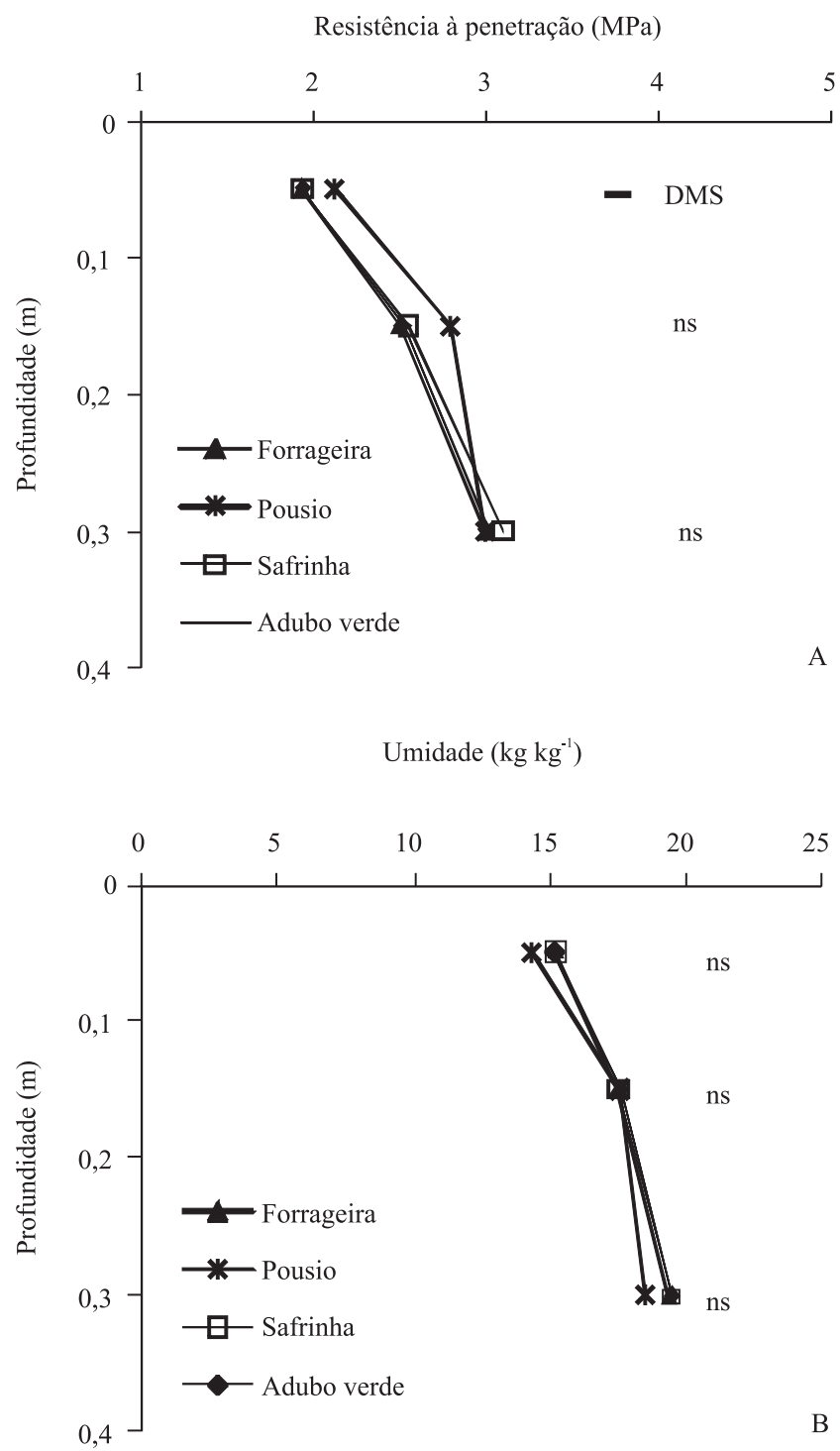

Figura 3. Resistência do solo à penetração $(A)$ e umidade do solo (B), em função dos sistemas de rotação de culturas: pousio, soja/pousio/milho/pousio; safrinha, soja/ aveia-branca/milho/feijão; adubo verde, soja/milheto/milho/ guandu; forrageira, soja/braquiária/milho/braquiária. ${ }^{\text {ns }}$ ão significativo. DMS, diferença mínima significativa a 5\% de probabilidade, pelo teste $\mathrm{t}$. 
verificou que a utilização, por três anos consecutivos, de milheto, sorgo forrageiro ou crotalária juncea, como plantas de cobertura na primavera, diminuiu a compactação do solo na camada de $0-0,05 \mathrm{~m}$, em comparação ao sistema com pousio nessa época. Calonego \& Rosolem (2010), em experimento com plantas de cobertura ou pousio em primavera, por três anos consecutivos, também relataram que o milheto, em sucessão ao triticale, e a crotalária, em sucessão ao triticale ou ao girassol, são boas opções para evitar que a densidade do solo atinja valores acima do considerado crítico, na camada de $0-0,20 \mathrm{~m}$.

\section{Conclusões}

1. A aplicação de corretivos da acidez na superfície do solo, em sistema plantio direto, não reduz a agregação do solo e aumenta a macroporosidade do solo, com efeitos mais pronunciados do silicato de cálcio e magnésio, em comparação ao calcário dolomítico, quando aplicados em profundidade.

2. A manutenção do solo em pousio, na entressafra, prejudica a sua estruturação, reduz a estabilidade dos agregados e aumenta a resistência à penetração nas camadas superficiais.

3. A semeadura de braquiária (Urochloa ruziziensis) entre as safras de verão aumenta a estabilidade de agregados nas camadas superficiais.

\section{Agradecimentos}

À Fundação de Amparo à Pesquisa do Estado de São Paulo, pelo apoio financeiro e pela concessão de bolsa; e ao Conselho Nacional de Desenvolvimento Científico e Tecnológico, pela concessão de bolsa.

\section{Referências}

ALBUQUERQUE, J.A.; BAYER, C.; ERNANI, P.R.; FONTANA, E.C. Propriedades físicas e eletroquímicas de um Latossolo Bruno afetadas pela calagem. Revista Brasileira de Ciência do Solo, v.24, p.295-300, 2000.

ALBUQUERQUE, J.A.; BAYER, C.; ERNANI, P.R.; MAFRA, A.L.; FONTANA, E.C. Aplicação de calcário e fósforo e estabilidade da estrutura de um solo ácido. Revista Brasileira de Ciência do Solo, v.27, p.799-806, 2003.

BAYER, C.; MIELNICZUK, J. Dinâmica e função da matéria orgânica. In: SANTOS, G. de A.; SILVA, L.S. da; CANELLAS, L.P.; CAMARGO, F.A. de O. (Ed.). Fundamentos da matéria orgânica do solo: ecossistemas tropicais e subtropicais. 2.ed.rev.atual. Porto Alegre: Metrópole, 2008. p.7-18.
BLANCO-CANQUI, H.; STONE, L.R.; STAHLMAN, P.W. Soil response to long-term cropping systems on an Argiustoll in the central Great Plains. Soil Science Society of America Journal, v.74, p.602-611, 2010.

BORTOLUZZI, E.C.; GARBOZZA, L.; GUARESCHI, C.; RHEINHEIMER, D. dos S. Efeito da calagem na relação entre solo e água. Revista Brasileira de Ciência do Solo, v.32, p.2621-2628, 2008.

BORTOLUZZI, E.C.; POLETO, C.; BAGINSKI, Á.J.; SILVA, V.R. da. Aggregation of subtropical soil under liming: a study using laser diffraction. Revista Brasileira de Ciência do Solo, v.34, p.725-734, 2010.

CALONEGO, J.C. Uso de plantas de cobertura na recuperação de solo compactado. 2007. 125p. Tese (Doutorado) - Universidade Estadual Paulista, Botucatu.

CALONEGO, J.C.; ROSOLEM, C.A. Estabilidade de agregados do solo após manejo com rotações de culturas e escarificação. Revista Brasileira de Ciência do Solo, v.32, p.1399-1407, 2008.

CALONEGO, J.C.; ROSOLEM, C.A. Soybean root growth and yield in rotation with cover crops under chiseling and no-till. European Journal of Agronomy, v.33, p.242-249, 2010.

CAMARGO, O.A. de; MONIZ, A.C.; JORGE, J.A.; VALADARES, J.M.A.S. Métodos de análise química, mineralógica e física de solos do Instituto Agronômico de Campinas. Ed.rev.atual. Campinas: Instituto Agronômico, 2009. 77p. (IAC. Boletim técnico, 106).

CASTRO FILHO, C.; MUZILli, O.; PODANOSCHI, A.L. Estabilidade dos agregados e sua relação com o teor de carbono orgânico num Latossolo Roxo distrófico, em função de sistemas de plantio, rotações de culturas e métodos de preparo de amostras. Revista Brasileira de Ciência do Solo, v.22, p.527-538, 1998.

CHAN, K.Y.; HEENAN, D.P. Lime-induced loss of soil organic carbon and effect on aggregate stability. Soil Science Society of America Journal, v.63, p.1841-1844, 1999.

CORRÊA, J.C. Efeito de sistemas de cultivo na estabilidade de agregados de um Latossolo Vermelho-Amarelo em Querência, MT. Pesquisa Agropecuária Brasileira, v.37, p.203-209, 2002.

CORRÊA, J.C.; BULL, L.T.; CRUSCIOL, C.A.C.; MORAES, M.H. Alteração de atributos físicos em Latossolo com aplicação superficial de escória de aciaria, lama cal, lodos de esgoto e calcário. Revista Brasileira de Ciência do Solo, v.33, p.263-272, 2009.

COSTA, F. de S.; BAYER, C.; ALBUQUERQUE, J.A.; FONTOURA, S.M.V. Calagem e as propriedades eletroquímicas e físicas de um Latossolo em plantio direto. Ciência Rural, v.34, p.281-284, 2004.

CUNHA, E. de Q.; BALBINO, L.C.; STONE, L.F.; LEANDRO, W.M.; OLIVEIRA, G.C. de. Influência de rotações de culturas nas propriedades físico-hídricas de um Latossolo Vermelho em plantio direto. Engenharia Agrícola, v.27, p.665-674, 2007.

GARCIA, R.A.; ROSOLEM, C.A. Agregados em um Latossolo sob sistema plantio direto e rotação de culturas. Pesquisa Agropecuária Brasileira, v.45, p.1489-1498, 2010.

GRABLE, A.R.; SIEMER, E.G. Effects of bulk density, aggregate size, and soil water suction on oxygen diffusion, redox potential 
and elongation of corns roots. Soil Science Society of America Journal, v.32, p.180-186, 1968.

GRIÈVE, I.C.; DAVIDSON, D.A.; BRUNEAU, P.M.C. Effects of liming on void space and aggregation in an upland grassland soil. Geoderma, v.125, p.39-48, 2005.

HUANG, S.; PENG, X.X.; HUANG, Q.R.; ZHANG, W.J. Soil aggregation and organic carbon fractions affected by long-term fertilization in a red soil of subtropical China. Geoderma, v.154, p.364-369, 2010.

JONG VAN LIER, Q. de. Física do solo. Viçosa: Sociedade Brasileira de Ciência do Solo, 2010. 298p.

KEMPER, W.D.; CHEPIL, W.S. Size distribution of aggregates. In: BLACK, C.A.; EVANS, D.D.; WHITE, J.L.; ENSMINGER, L.E.; CLARK, F.E. (Ed.). Methods of soil analysis. Madison: American Society of Agronomy, 1965. p.499-510.

MIELNICZUK, J. Matéria orgânica e sustentabilidade de sistemas agrícolas. In: SANTOS, G. de A.; CAMARGO, F.A. de O. (Ed.). Fundamentos da matéria orgânica do solo: ecossitemas tropicais e subtropicais. Porto Alegre: Genesis, 1999. p.1-8.

PEDROTTI, A.; PAULETTO, E.A.; GOMES, A. da S.; TURATTI, A.L.; CRESTANA, S. Sistemas de cultivo de arroz irrigado e a compactação de um Planossolo. Pesquisa Agropecuária Brasileira, v.36, p.709-715, 2001.

PÉRTILE, P. Resíduo alcalino da indústria de celulose em solos ácidos e área degradada. 2011. 106p. Dissertação (Mestrado) Universidade do Estado de Santa Catarina, Lages.

RAIJ, B. van; ANDRADE, J.C. de; CANTARELLA, H.; QUAGGIO, J.A. (Ed.). Análise química para avaliação da fertilidade de solos tropicais. Campinas: Instituto Agronômico, 2001. 285p.

SALTON, J.C. Matéria orgânica e agregação do solo na rotação lavoura-pastagem em ambiente tropical. 2005. 158p. Tese (Doutorado) - Universidade Federal do Rio Grande do Sul, Porto Alegre.

SALTON, J.C.; MIELNICZUK, J.; BAYER, C.; BOENI, M.; CONCEIÇÃO, P.C.; FABRÍCIO, A.C.; MACEDO, M.C.M.; BROCH, D.L. Agregação e estabilidade de agregados do solo em sistemas agropecuários em Mato Grosso do Sul. Revista Brasileira de Ciência do Solo, v.32, p.11-21, 2008.
SANTOS, C.A.; LANÇAS, K.P. Projeto e construção de um penetrômetro hidráulico-eletrônico. Energia na Agricultura, v.14, p.55-61, 1999.

SANTOS, H.G. dos; JACOMINE, P.K.T.; ANJOS, L.H.C. dos; OLIVEIRA, V.A. de; OLIVEIRA, J.B. de; COELHO, M.R.; LUMBRERAS, J.F.; CUNHA, T.J.F. (Ed.). Sistema brasileiro de classificação de solos. 2.ed. Rio de Janeiro: Embrapa Solos, 2006. $306 \mathrm{p}$.

SETA, A.K.; KARATHANASIS, A.D. Water dispersible colloids and factors influencing their dispersibility from soil aggregates. Geoderma, v.74, p.255-266, 1996.

SILVA, I.F.; MIELNICZUK, J. Ação do sistema radicular de planta na formação e estabilização de agregados do solo. Revista Brasileira de Ciência do Solo, v.21, p.113-117, 1997.

STONE, L.R.; SCHLEGEL, A.J. Tillage and crop rotation phase effects on soil physical properties in the West-Central Great Plains. Agronomy Journal, v.102, p.483-491, 2010.

TAVARES FILHO, J.; BARBOSA, G.M. de C.; RIBON, A.A. Physical properties of dystrophic Red Latosol (Oxisol) under different agricultural uses. Revista Brasileira de Ciência do Solo, v.34, p.925-933, 2010.

TORMENA, C.A.; ROLOFF, G.; SÁ, J.C.M. Propriedades físicas do solo sob plantio direto influenciadas por calagem, preparo inicial e tráfego. Revista Brasileira de Ciência do Solo, v.22, p.301-309, 1998.

WENDLING, B.; JUCKSCH, I.; MENDONÇA, E. de S.; NEVES, J.C.L. Carbono orgânico e estabilidade de agregados de um Latossolo Vermelho sob diferentes manejos. Pesquisa Agropecuária Brasileira, v.40, p.487-494, 2005.

WOHLENBERG, E.V.; REICHERT, J.M.; REINERT, D.J.; BLUME, E. Dinâmica da agregação de um solo franco-arenoso em cinco sistemas de culturas em rotação e em sucessão. Revista Brasileira de Ciência do Solo, v.28, p.891-900, 2004.

ZONTA, E.; BRASIL, F. da; GOI, S.R.; ROSA, M.M.T. da. O sistema radicular e suas interações com o ambiente edáfico. In: FERNANDES, M.S. (Ed.). Nutrição mineral de plantas. Viçosa: Sociedade Brasileira de Ciência do Solo, 2006. p.7-52.

Recebido em 4 de abril de 2011 e aprovado em 1 de dezembro de 2011 